ARTÍCULOS 



\title{
LA LEGITIMACIÓN DE LA REALEZA ENTRE LOS MAYAS DEL PRECLÁSICO TARDÍO. LOS MASCARONES DE EL TIGRE, CAMPECHE
}

\author{
ERnesto Vargas Pacheco \\ Instituto de Investigaciones Antropológicas \\ Universidad Nacional Autónoma de México
}

Resumen: En el arte monumental del periodo Clásico maya la imagen del señor ocupaba el sitio principal y todas las demás imágenes un lugar secundario. Con este trabajo se quiere demostrar que los soberanos mayas ya en el Preclásico Tardío, o desde antes, usaron la arquitectura para reproducir la topografía del universo y se sirvieron de los mascarones para transmitir la condición divina de sus antepasados, de sus dioses y la suya propia.

En El Tigre, Campeche, se han explorado varios mascarones de estuco del Preclásico Tardío, que representan rostros humanos, los cuales bien podrían identificarse como ancestros: antepasados de gobernantes que pretenden divinizarlos para así legitimizar la realeza maya.

Palabras clave: mayas, Campeche, mascarones, realeza divina, Preclásico Tardío.

AвSTRACT: The images of Maya dignitaries take the most important places in monumental art during Classic period, and all other representations occupy a secondary position in that context. This paper pretends to demonstrate that Maya kings tried to duplicate their conception of the Universe on civic architecture since Preclassic period, or even before; they used huge mask representations to transmit the sacred condition of their ancestors, their gods and their selves.

At El Tigre site, in Campeche, have been explored several stucco masks of Late Preclassic date, showing human faces that may represent ancestors of the kings who tried to deify them in order to legitimate Maya royalty.

KeYwords: Maya, Campeche, stucco masks, sacred royalty, Late Preclassic.

RECEPCIÓN: 8 de junio de 2010.

ACEPTACIÓN: 31 de agosto de 2010. 



\title{
LA LEGITIMACIÓN DE LA REALEZA ENTRE LOS MAYAS DEL PRECLÁSICO TARDÍO. LOS MASCARONES DE EL TIGRE, CAMPECHE
}

\author{
ERnesto Vargas Pacheco \\ Instituto de Investigaciones Antropológicas \\ Universidad Nacional Autónoma de México
}

\section{Introducción}

Para el Clásico la mayor parte de las representaciones del cosmos corresponden al entorno del soberano: al colocar al jerarca en el centro del universo, se le confiere una dimensión realmente universal. En el arte monumental la imagen del señor ocupa el sitio principal y todas las demás imágenes o seres naturales ocupan un lugar secundario y carecen de existencia independiente.

Los soberanos mayas conmemoraban sus actos rituales a través del arte y la arquitectura monumental y los señores del Preclásico Tardío de El Tigre usaron la arquitectura para reproducir la topografía del universo y se sirvieron de los mascarones para trasmitir la condición divina de sus antepasados, de sus dioses y la suya propia, pues ellos eran los que intervenían ante los dioses para asegurar las cosechas abundantes, eran los que convocaban la lluvia y la fertilidad y poseían el poder para obligar a esas fuerzas sobrenaturales, a través del ritual, a obrar en beneficio del pueblo.

Entre el 250 a.C. y el 100 d.C. se observa un auge de la construcción monumental en todo el área maya; a partir del Preclásico Tardío las construcciones en forma de pirámides de base muy amplia fueron hechas en piedra caliza labrada y recubiertas de estuco. En algunos casos, es evidente el uso de pintura roja y negra sobre muros y pisos estucados. Los montículos más grandes, como los de Calakmul y El Mirador, de alguna manera representan la culminación de una tendencia generalizada en Mesoamérica de crear "montañas” artificiales (Hansen, 1990 a y b).

Por mucho tiempo se planteó al periodo Clásico como el de mayor expresión de la cultura maya, pero ahora, con los descubrimientos recientes en diversos sitios, el periodo Preclásico ha cobrado gran importancia. Actualmente se debe ver este gran desarrollo como parte de una secuencia evolutiva de interrelación regional en donde existen semejanzas cerámicas, arquitectónicas y escultóricas en una gran área.

La presencia de los mascarones de estuco modelado, elementos iconográficos, la Montaña Sagrada (Witz) y el dios Bufón (Jester God) en asociación con arquitec- 
tura monumental, permiten plantear que en las Tierras Bajas Centrales existió un complejo político y religioso de gran importancia. Además, la aparición de algunas deidades, genealogías, rituales de ascensión y otros eventos, tienen un origen Preclásico.

Algunos de los datos obtenidos hasta la fecha en el Proyecto Arqueológico de El Tigre, Campeche, nos ayudan a entender un poco más el proceso cultural de los primeros asentamientos mayas y sobre todo la relación que tuvieron los habitantes del río Candelaria con los del Petén guatemalteco. De esta manera, la región de ríos y lagunas de Tabasco-Campeche durante el Preclásico se integra más a los sitios del norte del Petén y a la región de Calakmul.

Al parecer, durante el Preclásico Tardío la ideología religiosa representó la cristalización de la autoridad absoluta de los soberanos mayas en el norte del Petén. Se construyeron edificios de patrón triádico de un tamaño jamás repetido en el mundo maya, y se realizaron construcciones a gran escala en el norte del Petén: Nakbé, El Mirador, Tintal y Güiro (Hansen, 1990a; Matheny, 1987).

En El Tigre se han excavado tres estructuras (figura 1) que denotan la gran importancia del sitio durante el Preclásico Tardío; en 1984 se excavó la Estructura 2, en donde se encontró un mascarón del tipo característico de Uaxactún. La estructura mide aproximadamente unos $20 \mathrm{~m}$ de altura y asociadas al mascarón se hallaron cerámicas características del Preclásico Tardío.

Entre 1997 y 1998 se excavó la Estructura 1 (figura 2), en donde apareció la Plataforma 1C Sub que presenta los mascarones antropomorfos, tiene un solo

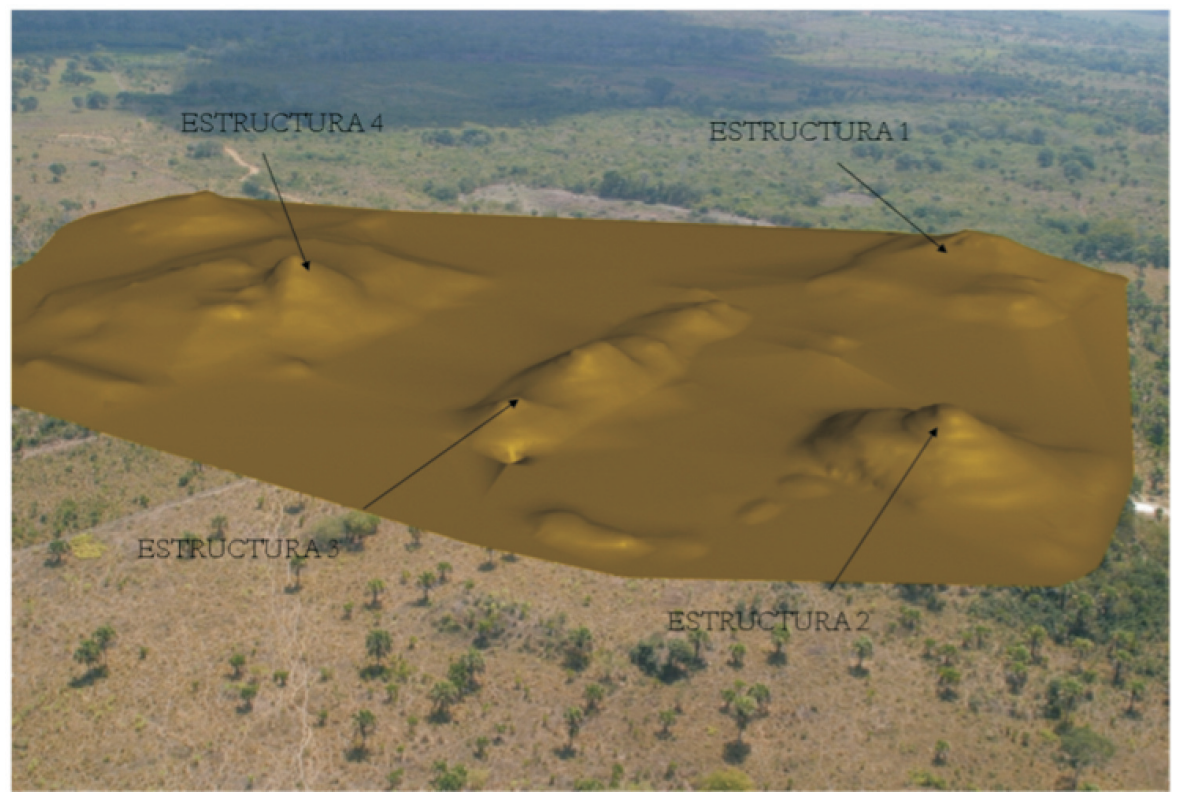

Figura 1. Centro ceremonial de El Tigre 


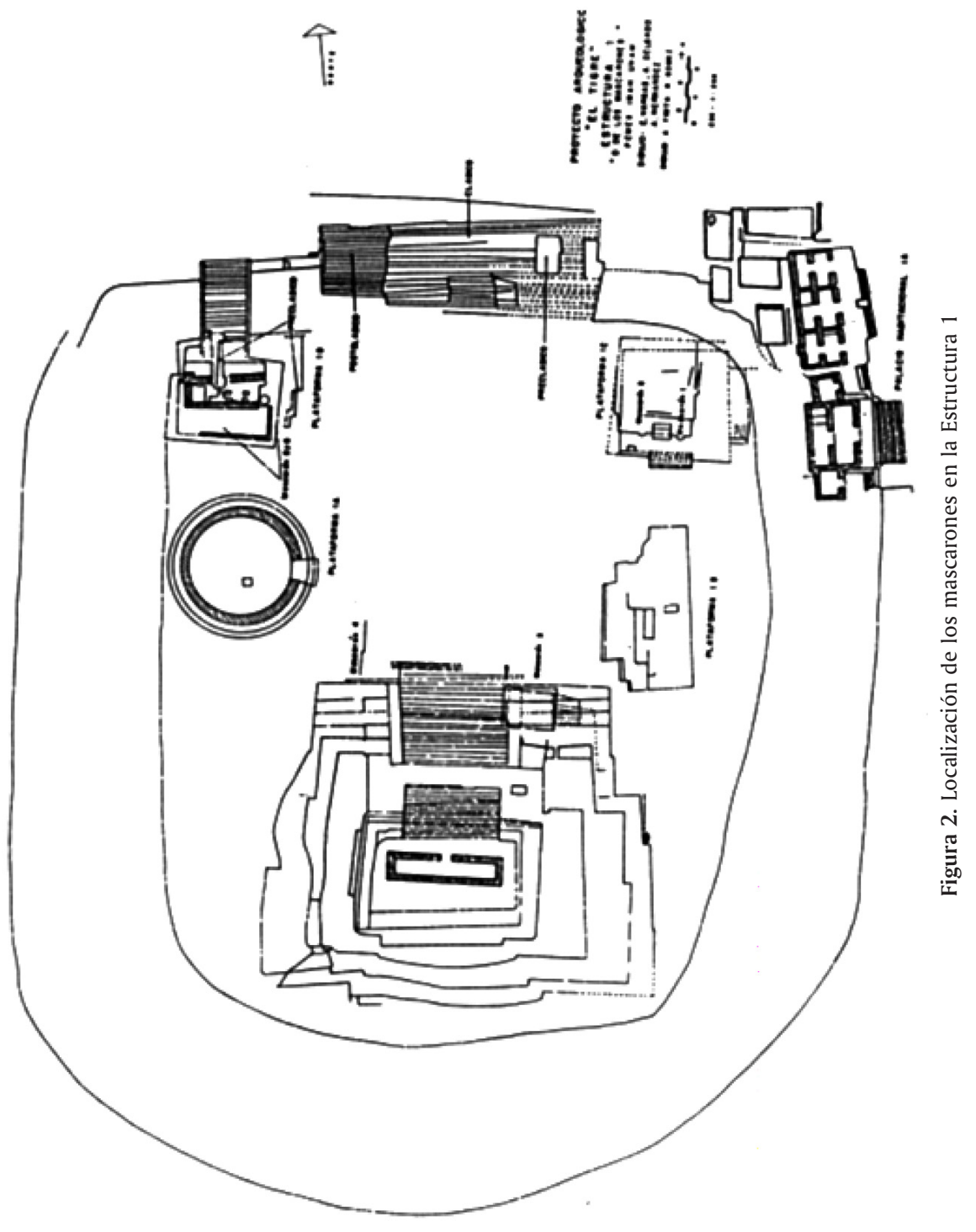


cuerpo o nivel y, al parecer, sólo contaba con una escalinata en la fachada sur. Es difícil reconocer si los recintos fueron techados con mampostería o con palmas de huano debido a que nada más quedaron los pisos. Sin embargo, es casi seguro, por la época a que nos referimos, que fueran de materiales perecederos. La reconstrucción de la Plataforma 1C Sub, en la Plataforma 1C, ilustra la situación de los mascarones y el estilo típico del Petén en los taludes y el remetimiento de las esquinas. Los mascarones están dispuestos a los lados de una escalinata central (figura 3). Si El Tigre debiera adquirir importancia en el mundo maya sería por los mascarones, pues hemos localizado más de 10 .

\section{La legitimación de la realeza}

Los soberanos mayas conmemoraban sus actos rituales a través del arte y la arquitectura monumental. Los reyes usaban la arquitectura para reproducir la topografía
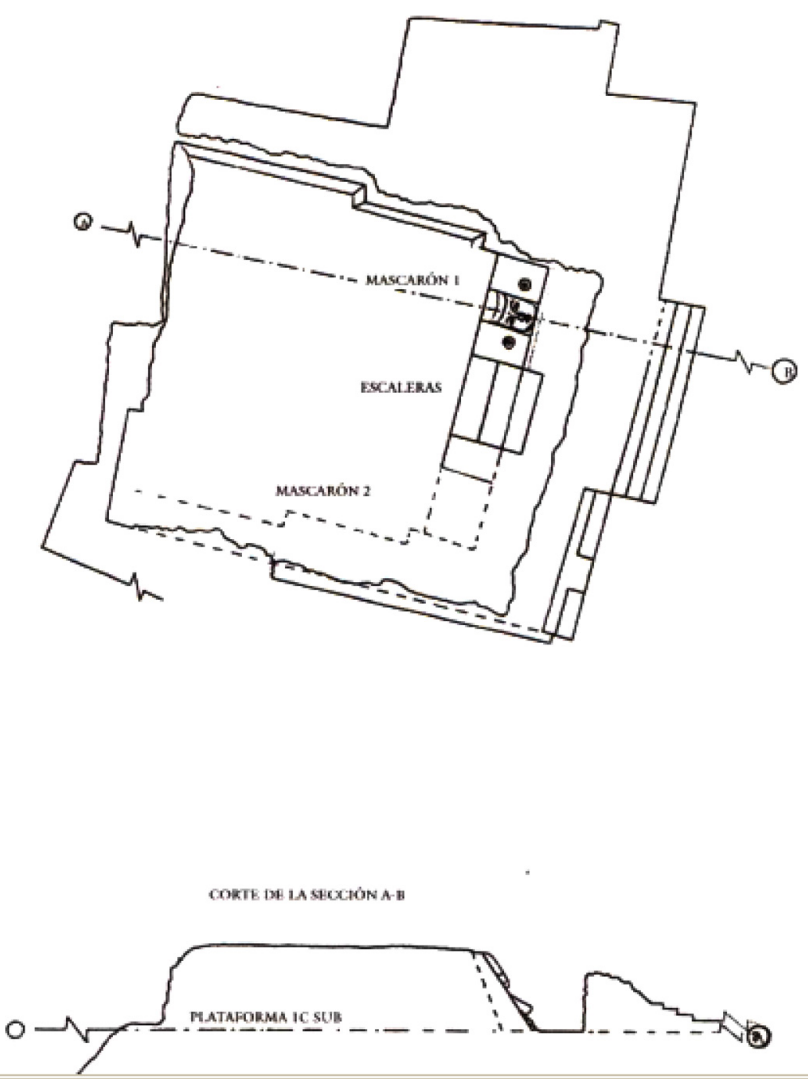

Figura 3. Dibujo de la Plataforma 1C, con la localización de los mascarones 
del universo; es decir, una pirámide se reconocía como una montaña sagrada (Witz), mientras que las plazas circundantes eran percibidas como lagos simbólicos (naab'). A menor escala, los reyes mayas utilizaban objetos como símbolos del mundo físico y el universo divino para transmitir principios cósmicos a través de un rico repertorio iconográfico.

Durante el Preclásico Tardío los mascarones en las fachadas fueron una decoración arquitectónica frecuente en las Tierras Bajas Mayas y se piensa que los temas representados simbolizan la cosmovisión maya a gran escala; y el papel del rey se legitimaba mediante las actividades rituales que se ejecutaban en estas estructuras. Hasta hace poco tiempo los testimonios sugerían que este estilo de arquitectura surgió abruptamente durante el Preclásico Tardío, pero ahora se sabe que nació antes.

Lo más llamativo de las exploraciones realizadas en El Tigre fue el estudio de los seis mascarones localizados en la Estructura 1, dos en la Estructura 4 y tres en la Estructura 2. En El Tigre la localización de mascarones en contextos ceremoniales de subestructuras, es decir, integrados a los templos piramidales presupone su utilidad religiosa desde los inicios de las construcciones en el Preclásico Tardío.

Por lo tanto, la particularidad de los mascarones debe ser vista como parte de un largo proceso de aceptación y profusión en el que los elementos constitutivos, la disposición y la escala de manejo serán variaciones de un mismo sistema de valores que se refleja también en una larga tradición.

Estos testimonios indican que durante los siglos I y II antes de Cristo se había desarrollado un sistema fuerte de gobierno centralizado, con un soberano apoyado por un grupo de nobles, sacerdotes que formaban la corte. Estos soberanos proclamaban ser descendientes directos de los dioses, y dado que esto les confería el derecho de gobernar los destinos de su pueblo, no perdían ninguna oportunidad de recalcar su naturaleza divina ante los súbditos. Los dirigentes emprendieron grandes obras y programas para exhibir su autoridad y la de sus dioses; por eso mandaron construir edificios y mascarones dedicados a sus antepasados deificados puesto que la posición de un soberano dependía de su capacidad para acceder al poder natural y al sobrenatural. Tales proclamaciones de su capacidad espiritual en los monumentos públicos contribuían a validar semejante condición ante su pueblo.

La mayor parte de las representaciones del cosmos durante el Clásico corresponden al entorno del soberano. Al colocar al jerarca en el centro del universo, se le confiere una dimensión realmente universal. Estos mascarones bien pueden retratar a los ancestros de los gobernantes con aspecto de deidades que proclaman su autoridad sagrada y secular para proporcionar fertilidad y abundancia agrícola a sus comunidades. Estos soberanos encarnaban un sistema de gobierno conocido como realeza divina, un fenómeno que se encuentra entre las civilizaciones antiguas en todo el mundo y la maya no es la excepción.

Uno de los deberes más antiguos del ajaw era interceder ante los dioses para asegurar una cosecha abundante. La comunicación con los antepasados era la 
fuente primordial de la sabiduría y la legitimidad, era otro de los deberes del soberano, y también uno de los más antiguos y mas teatralizados, envuelto en rituales que eran indispensables para conseguir esa comunicación.

La naturaleza esencial de la antigua realeza maya se apoya en el concepto de que los rituales más importantes que celebraba el rey suponían recrear los acontecimientos de la creación (Freidel y Schele, 1993). El arte monumental olmeca retrata a los gobernantes humanos con aspectos de deidades, sobre todo el dios del maíz, que proclaman su autoridad sagrada y secular para proporcionar fertilidad y abundancia agrícola a sus comunidades.

En las últimas décadas arqueólogos, epigrafistas e historiadores del arte han escrito sobre la posibilidad de que los soberanos encarnaran un sistema de gobierno conocido como realeza divina, en donde se supone que los ajaw recurrieron a toda una serie de situaciones para legitimar el poder de los soberanos mediante la sanción sobrenatural de sus patrones y antepasados sobrenaturales.

El ceremonial maya se centra en la recreación del cosmos bajo el aspecto del dios del maíz (Freidel y Schele, 1993: 55). Entre los actos rituales mas importantes que llevaban a cabo los reyes se encontraba el de elevar un gran árbol del mundo para separar el cielo de la tierra. El árbol del mundo suele identificarse como una ceiba, pero cuando el árbol era representado por una planta de maíz con fruto simbolizaba los actos de la creación.

Las élites recreaban y manipulaban las fuerzas cósmicas, el orden cósmico y las fuerzas de la naturaleza tan necesarias para la prosperidad agrícola y espiritual. Mediante estos actos ceremoniales el soberano afirmaba su papel en la recreación del mantenimiento de las fuerzas cósmicas del mundo maya para su comunidad, que se congregaba en la plaza para contemplar la ejecución, el control de dichas energías por parte del soberano.

Los reyes más antiguos se representaban con los ropajes del dios del maíz, para encarnar así el poder sagrado que garantizaba cosechas abundantes. El ritual primario de la realeza era establecer el cosmos cuatripartito para simbolizar la milpa, o campo de maíz, con el rey vestido de deidad del maíz como eje central del universo.

La corona real de los primeros reyes mayas al parecer se originó entre los olmecas en el Preclásico Medio; el emblema del trifolio, que representa la planta de maíz, apareció como adorno en la frente del dios del maíz olmeca y más tarde se convirtió en la joya preciosa, o sak hu'unal, que identificó a los reyes mayas durante más de mil años.

El título de ajaw reconocía al rey como "hablador", cuya voz reflejaba no sólo su autoridad terrenal, sino también su capacidad de comunicarse con seres sobrenaturales y antepasados (Fields, 1989; Houston y Stuart, 2001). Otra posibilidad es que el título de ajaw proceda de una raíz antigua con el significado de "plantar semillas", lo que destacaría el papel de "sembrador" (Mathews y Justeson, 1984) y reafirmaría que el poder del rey tenía origen agrícola y estaba relacionado con la fertilidad y la abundancia de cosechas para su pueblo. 


\section{Los mascarones de El Tigre}

\section{Los mascarones 1 y 2 de la Estructura 1}

Los mascarones 1 y 2 (figura 4) se localizan en la Plataforma 1C y pertenecen a una subestructura que, por sus características, es del Preclásico Tardío, lo mismo que por la cerámica que se obtuvo durante las exploraciones. Sin embargo, el Mascarón 1 se parece mucho a los de Kohunlich que son del Clásico Temprano, motivo por el cual se pensaba que dicho mascarón era también de ese periodo. Se localizan a ambos lados de una escalinata que pertenece a una plataforma baja; a los lados de dicha escalera se pusieron los mascarones que ocupan gran parte del talud.

El mascarón del lado este es un rostro humano; está bastante bien conservado pues se distinguen todos los elementos componentes: barbilla, boca, nariz, pómulos, tocado y dos orejeras muy amplias a los lados. Todo el personaje está pintado de color rojo. El Mascarón 2 no está en muy buenas condiciones, pues el rostro ha desaparecido casi en su totalidad; sin embargo, una de las orejeras está en magnífica condición, pues no sólo se encontró el estuco que la decoró sino también su pintura. La otra, en cambio, fue totalmente destruida, es de suponerse que al momento de hacer el edificio que los tapó. El tocado de este

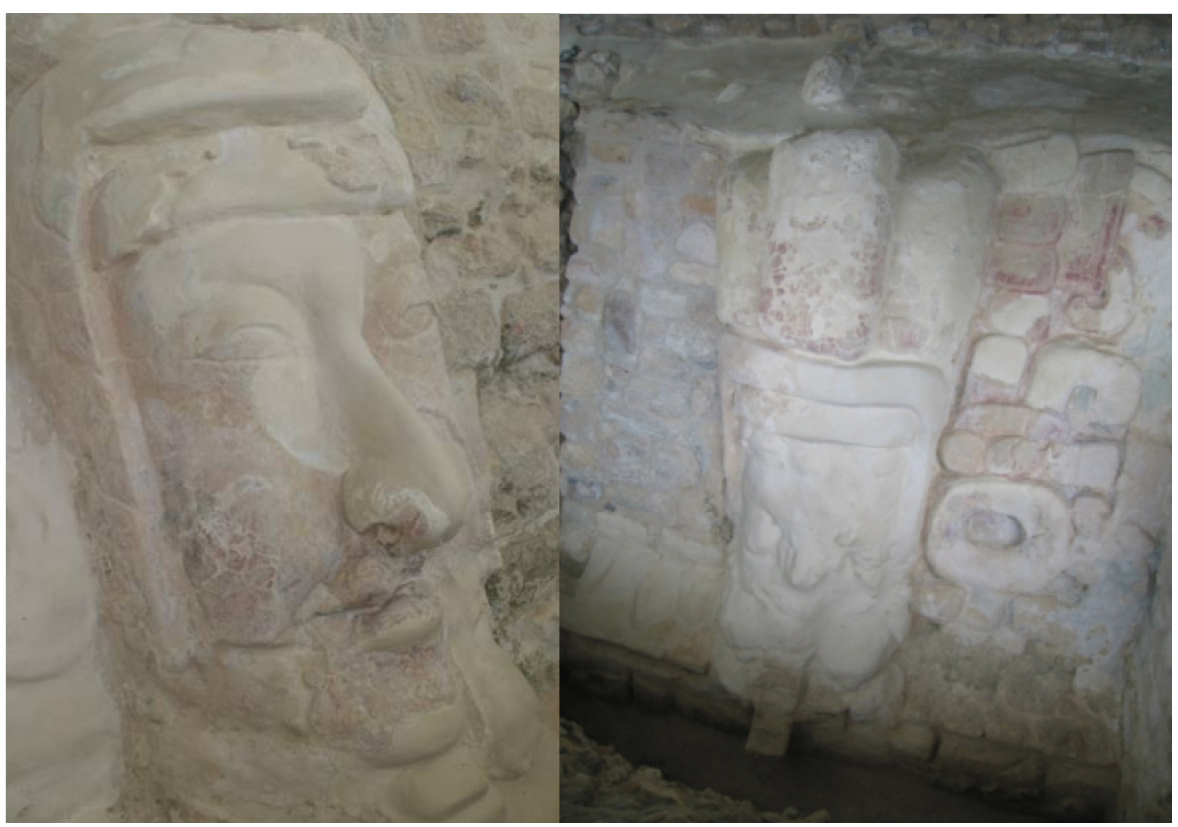

Figura 4. Vista de los mascarones 1 y 2 de la Plataforma 1C Sub 
mascarón, a pesar de encontrarse en malas condiciones, fue muy bien restaurado y se pudo recuperar en gran medida.

Estos dos mascarones representan sin lugar a duda a personajes importantes del lugar, seguramente antepasados deificados según se deduce por los elementos que encontramos asociados, tales como la pintura roja en el rostro, las orejeras y el tocado, entre otros.

Los símbolos que presentan los mascarones 1 y 2 de la Estructura 1 (figura 5) son de realeza, que en tiempos posteriores aparecerán en la iconografía y en las fuentes históricas mayas. Para Matheny (1987: 330) las orejeras y bandas anudadas son símbolos que se pueden ligar posiblemente a una deificación posterior de los personajes allí representados. Por otra parte, estos personajes podrían representar el origen de los primeros grupos de linaje que durante el Clásico serán los principales. Las hojas, además, pueden representar la fertilidad que también está relacionada con los gobernantes. El halach uinic no solamente jugaba el papel de intermediario entre los dioses y los hombres, sino también prometía la fertilidad de la tierra a todos sus habitantes y legitimaba el linaje dominante y, por lo tanto, el poder de los oficiales pertenecientes al mismo. Esta es una justificación del poder con base en la cosmovisión del grupo que aseguraba mantener, en primer lugar, la cohesión de todos los miembros de los grupos gobernantes subordinados y, en segundo, el poder sobre el común del pueblo al cual garantizaba la armonía y la fertilidad (Okoshi Harada, 1995: 23-24).

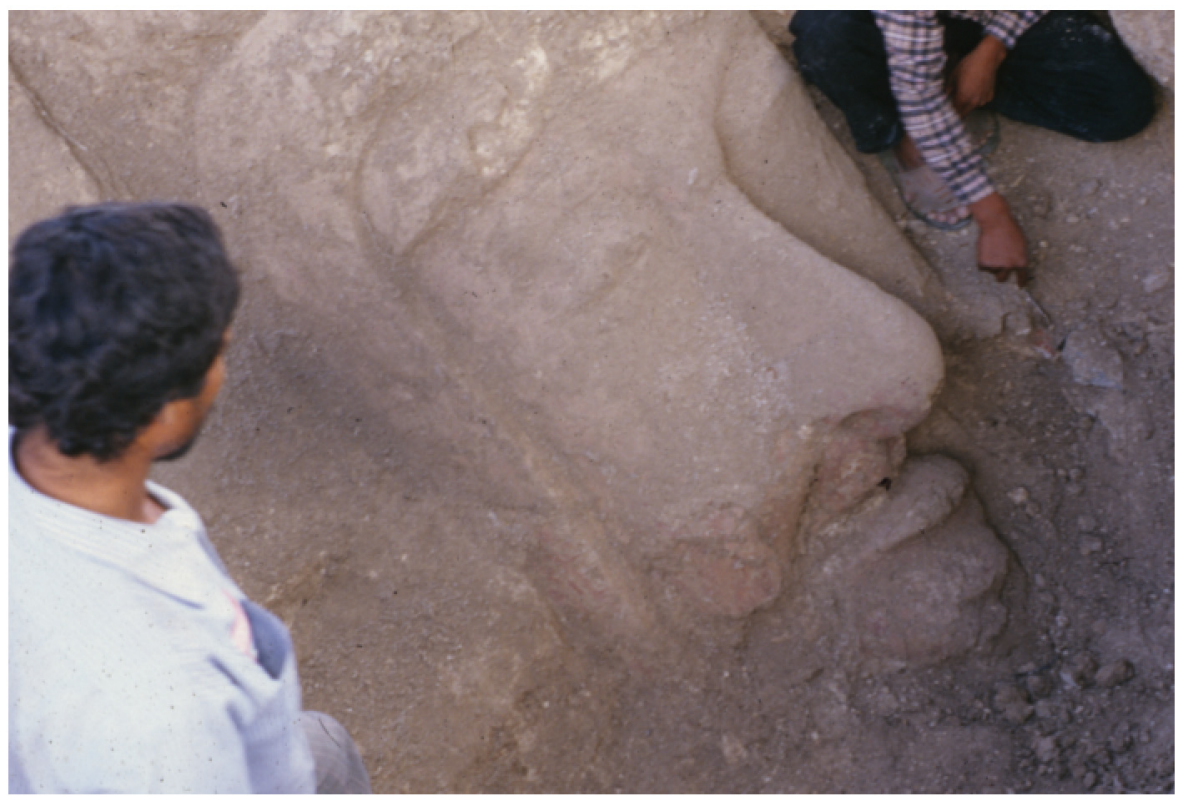

Figura 5. Mascarón 1 de la Estructura 1, durante las exploraciones 
El yelmo o casco que portaban los gobernantes simboliza al dios Bufón; debemos recordar que ese elemento aparece desde el Preclásico Tardío como un distintivo de parentesco que denota la presencia de poder y, según Freidel y Schele (1988: 552), es uno de los objetos simbólicos del poder entre los mayas. El soberano es una figura omnipresente en las estelas mayas del Clásico; representaba las fuerzas de ordenamiento de las distintas regiones del cosmos y el territorio del reino. Convocaba la lluvia y la fertilidad, disfrutaba de la protección de los antepasados fundadores, y poseía el poder para obligar a esas fuerzas a obrar en beneficio de su pueblo. Uno de sus deberes principales era interceder ante los dioses para asegurar una cosecha abundante; otro era la comunicación con los antepasados, de allí la importancia de representarlos en estos mascarones del Preclásico Tardío.

Durante el Preclásico Tardío los mascarones en las fachadas fueron una decoración arquitectónica frecuente en las Tierras Bajas Mayas. Aunque los temas iconográficos varían de un sitio a otro, estas máscaras comparten ciertos elementos que expresaban ideas sobre la cosmovisión maya y legitimaban el papel de la realeza (Freidel y Schele, 1988; Garben et al., 2004; Hansen, 1990a). Estos autores argumentan que la institución del ajaw se desarrolló durante el Preclásico Tardío, lo cual resultaría evidente en los sistemas de símbolos materiales. Sugieren que la realeza surgió en aquella época para reacomodar las contradicciones en la sociedad maya entre una ética de igualitarismo y un Estado real de elitismo floreciente, surgido a causa del eficaz comercio e interacción entre los mayas de las Tierras Bajas y sus vecinos, jerárquicamente organizados a lo largo del Preclásico. Los temas iconográficos de los mascarones en las fachadas simbolizan la cosmovisión maya a gran escala; el papel del rey se legitimaba mediante las actividades rituales que se ejecutaban en estas estructuras.

En El Tigre, la localización de mascarones en contextos ceremoniales de subestructuras, es decir, integrados a los templos piramidales presupone su utilidad religiosa desde los inicios de las construcciones. La orientación de sus fachadas hacia el interior de los patios y su ubicación preferente hacia los puntos específicos del horizonte resalta su importancia simbólica y cosmológica. Y la composición tripartita de los elementos constitutivos (orejera-rostro-orejera) que flanquean el acceso a los templos, es una tradición proveniente del Petén que se populariza y evoluciona hasta la región norte de la península de Yucatán (Vargas Pacheco, 2001: 103). Por lo tanto, la particularidad de los mascarones debe ser considerada como parte de un largo proceso de aceptación y profusión en el que los elementos constitutivos, la disposición y la escala de manejo son variaciones de un mismo sistema de valores que se refleja también en una larga tradición alfarera como es el tipo Sierra Rojo o las remodelaciones y desmantelamientos constructivos hechos con el propósito de renovar el espíritu cosmológico.

Los mascarones 1 y 2 son contemporáneos con el Mascarón 3 pues los niveles de los pisos son los mismos. Estos mascarones, como dijimos, son populares durante todo el periodo Preclásico Tardío, en casi toda el área maya de las Tierras 
Bajas. La cerámica conocida como Sierra Rojo durante ese periodo es también muy común en todos los rellenos constructivos de las subestructuras de El Tigre. Sin embargo, el problema del rango cronológico del tipo cerámico Sierra Rojo es que abarca muchos siglos de continuidad y no permite precisar el tiempo específico de los periodos de construcción de las edificaciones en El Tigre, que es donde abundantemente aparece en casi todos los rellenos constructivos, asociados a subestructuras. Este es el caso de las Plataformas 1B y 1C Sub, en donde se encuentran cuatro mascarones.

Es interesante resaltar el hecho de que los mascarones 1 y 2 están al frente del Mascarón 3. Como hemos dicho, los primeros se refieren seguramente a antepasados deificados, mientras el Mascarón 3 representa a un dios que bien puede ser Itzamnaaj con dos personajes de ancestros en el nivel celeste, lo cual es muy significativo pues aquí aparecen juntos tanto dioses como ancestros (figura 6). Estos soberanos de alguna manera proclamaban ser descendientes directos de los dioses, y esto les confería el derecho de gobernar los destinos de su pueblo, recalcando su naturaleza divina ante los súbditos.

\section{Los mascarones de la Estructura 2}

Como hemos expuesto, un rasgo característico del sitio arqueológico de El Tigre, correspondiente al Preclásico Tardío, es el de contar con mascarones como adorno en los edificios. Ya se sabía que la Estructura 2 (figura 7) tenía mascarones, pues en 1984 durante las exploraciones se habían encontrado los restos de dos de ellos, semidestruidos por los saqueadores. En la parte superior de la estructura el pozo de saqueo había dejado al descubierto parte de dos mascarones (figura 8). El primero de ellos muestra los restos de una orejera y parte del rostro de la figura principal que, al parecer, se trata de un felino; conservaba restos de pintura roja y negra. El mascarón estuvo adosado a una pared en donde estuvieron la orejera y los lazos que adornaban los lados de la pieza. Al fondo se

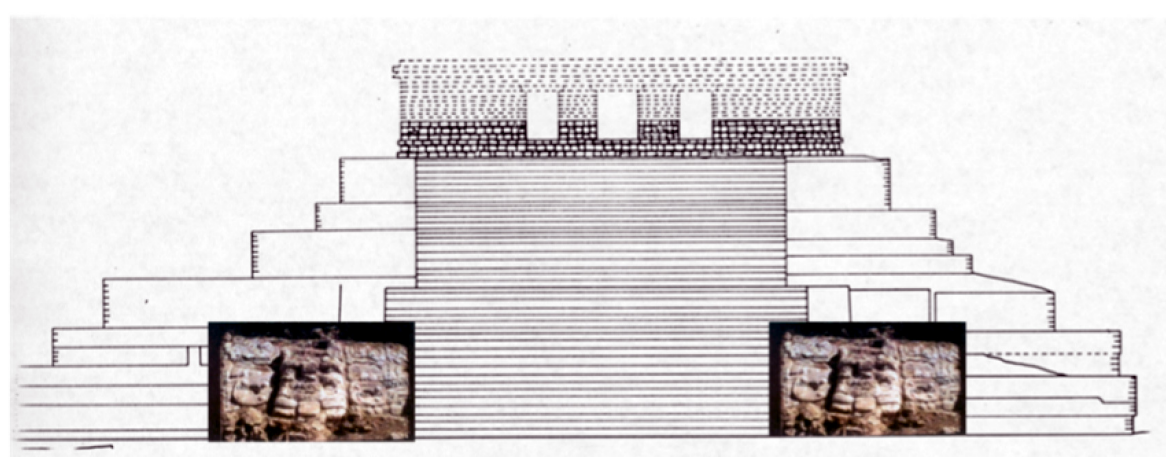

Figura 6. Dibujo reconstructivo de la Estructura 1 con los mascarones 3 y 4 que posiblemente representen a Itzamnaaj 


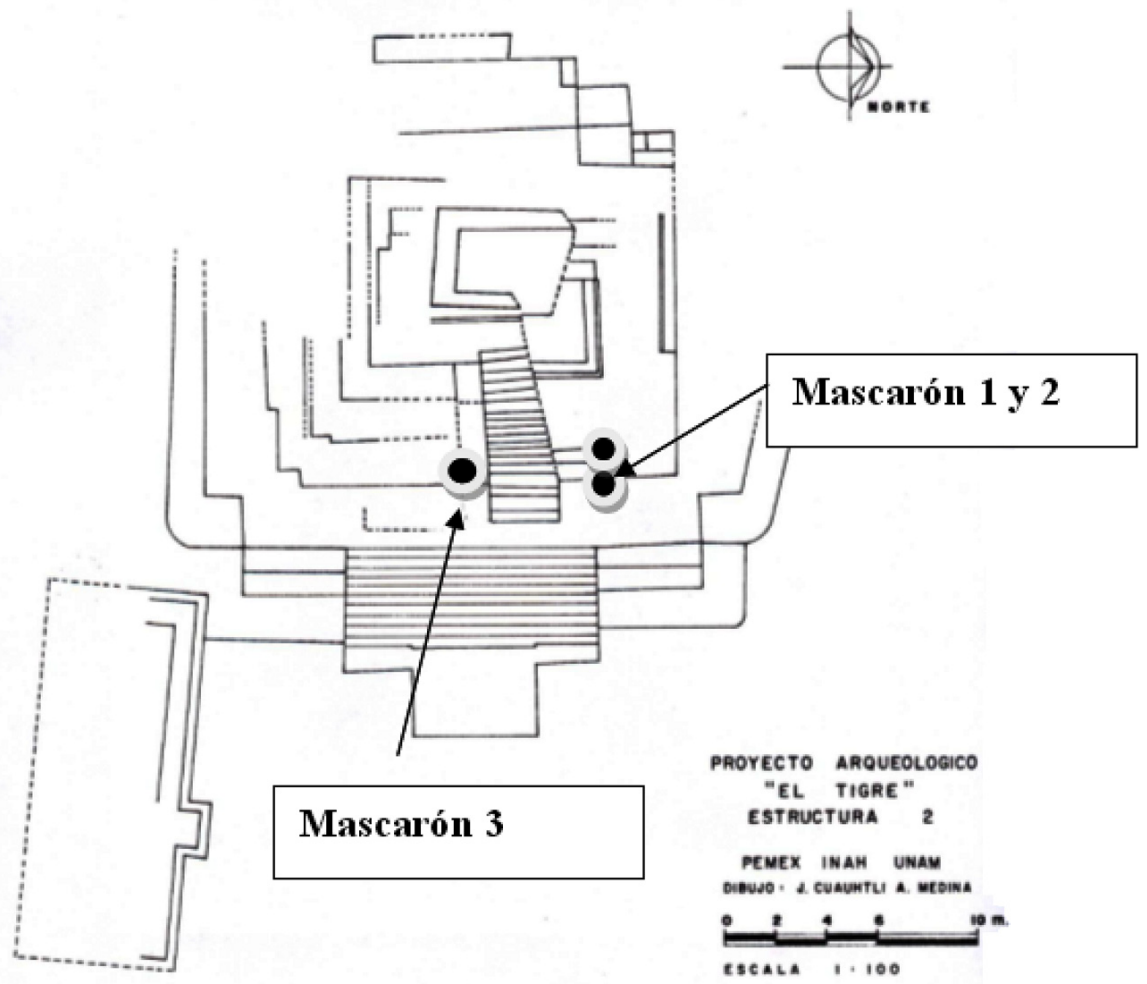

Figura 7. Plano de la Estructura 2

pueden ver los restos de una escalinata en muy buen estado de conservación. El material cerámico que salió asociado al mascarón es del Preclásico Tardío, y se trata de la cerámica conocida como Sierra Rojo.

Se pudo comprobar que existen tres etapas constructivas. En el primer plano está el Mascarón 1, que como dijimos representa a un felino y que sin lugar a dudas es del Preclásico Tardío. Posteriormente fue tapado por otro mascarón que no puede apreciarse en esa figura pero conserva todavía los restos de las orejeras pintadas de rojo y cuya forma es de una especie de semicírculo. Desagraciadamente este mascarón fue casi destruido en su totalidad por el pozo de saqueo (figura 9).

El Mascarón 1 fue explorado, como mencionamos, en la temporada de campo de 1984. En esa época no se tenía un gran conocimiento sobre los mascarones del Preclásico, motivo por el cual nos llamó poderosamente la atención que estuvieran asociados con la cerámica Sierra Roja. La excavación que se hizo dejó al descubierto los restos de un mascarón adosado a una pared de piedra caliza que estaba pegaba a una escalinata; entre la escalinata y el mascarón se encontraba 


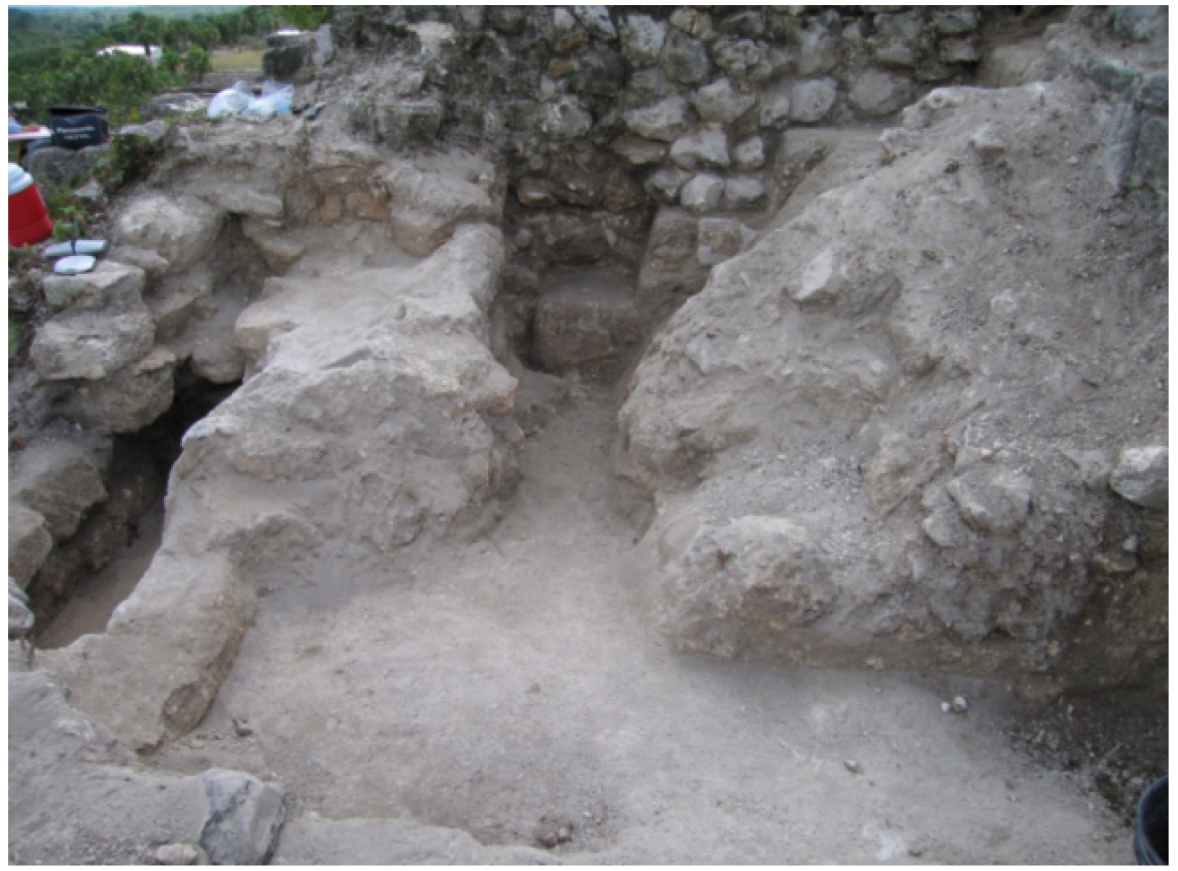

Figura 8. Restos de dos mascarones

un espacio que tenía una orejera y bajo ella se hallaba un elemento llamado "lazos", que a su vez se unía a otro elemento trilobular, el cual posteriormente fue identificado como hojas o plantas. Este mismo diseño se repetía al otro lado del mascarón.

Durante la temporada de campo del 2006, realizamos las exploraciones para conocer las etapas constructivas que tenía el edificio y en términos generales podemos decir que existen tres etapas constructivas muy bien definidas por la localización de los mascarones 1 y 2 , en donde el Mascarón 2 (figura 10) tapa al mascarón 1 y posteriormente se levanta un muro que tapa al Mascarón 2. Por otra parte son fácilmente identificables estas tres etapas constructivas mediante las tres escalinatas sobrepuestas. La dificultad se presentaba en la parte norte en donde encontramos varios muros que al principio fue difícil identificar con una etapa constructiva determinada, pero conforme avanzaron las exploraciones pudimos hacerlo y aclarar que algunos muros correspondían a la misma etapa y eran cuerpos del edificio, no etapas constructivas.

El Mascarón 3 representa un rostro humano bastante bien conservado y sin lugar a dudas se trata de un ancestro deificado. Se localiza en el lado sur del edificio y no se conocía su existencia, pero los hallazgos realizados en el lado norte hacían suponer que ahí debería de estar en muy buen estado de conservación 


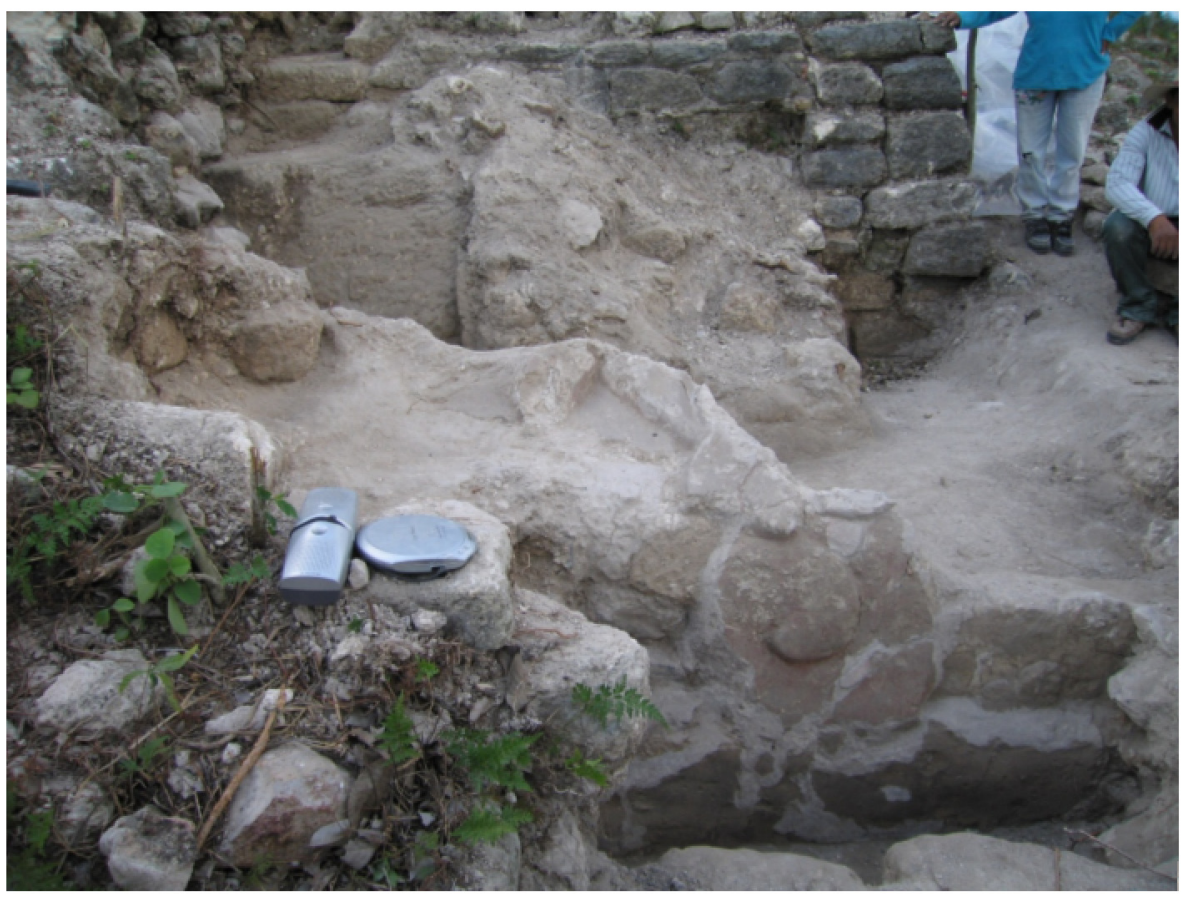

Figura 9. Restos de las orejeras del segundo mascarón

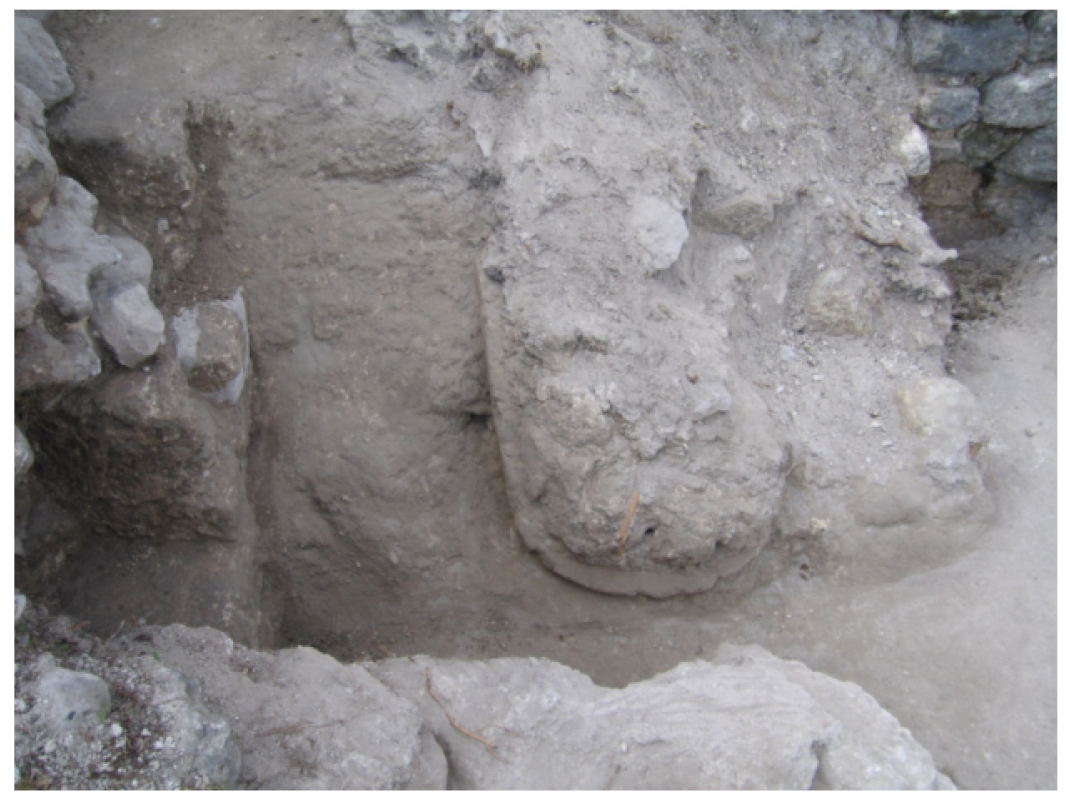

Figura 10. Mascarón 1 de la Estructura 2 
otro mascarón, motivo por el cual se llevaron a cabo dichas exploraciones y dio como resultado su localización.

Como explicamos, la Estructura 2 había sido explorada en 1984 y desde entonces nunca mas había sido intervenida. Muchos de los muros y parte de las escalinatas casi se habían desplomado, los muros del lado sur estaban vencidos y presentaban cuarteaduras muy grandes; esto motivó a buscar las bases para poderla consolidar bien. Mediante las exploraciones nos dimos cuenta que dichos muros no tenían bases y casi estaban en el aire. A los pocos centímetros encontramos restos de una subestructura; al ampliar las exploraciones apareció la base de un rostro humano, delimitado por un elemento que formaba la cara del personaje. En ese momento pudieron apreciarse los restos de la boca y de la nariz, lo mismo que otros elementos debajo de la barbilla.

Se siguió con la exploración de todo el rostro (figura 11) pudiendo observarlo completo con su cara, ojos, nariz y un tocado que cubría la parte superior de la cabeza. En términos generales podemos decir que se trata de un personaje en muy buen estado de conservación: todavía se advierten restos de pintura roja en todo el rostro y los elementos principales del tocado, que posteriormente pudimos definirlos como un tocado de ave, pues nos fue posible apreciar con claridad el pico del ave y los ojos.

Debajo de la barbilla pudimos apreciar algunos elementos no muy claros al principio, pero después de las exploraciones se puede decir que se trata de un dios del inframundo que bien puede ser Cauac (figura 12).

El lado derecho del mascarón tiene una orejera en bastante buen estado de conservación, la cual puede apreciarse perfectamente (figura 13) junto con lazos que unen los elementos superiores e inferiores en donde se pueden ver varias hojas al nivel en donde se encuentra el personaje del inframundo.

Como mencionamos, los mascarones 1 y 2 fueron tapados porque en términos generales estaban bastante destruidos. Sin embargo, el Mascarón 3 está en bastante buen estado de conservación, motivo por el cual se delimitó en ambos lados y no se exploró en su totalidad, sino que se cubrió con una capa de sascab mientras se hacía una estructura de madera con lámina de plástico para protegerlo de la lluvia y del sol. También se reforzaron los lados y la parte superior para protegerlo de la humedad. No se hizo ninguna intervención ni resane sobre el mascarón. Se trata de uno antropomorfo, de estuco, que se ubica al costado sur de la tercera escalinata, literalmente bajo tres cuerpos laterales que habían sido consolidados en la primera temporada de campo realizada en 1984.

Durante la exploración del rostro del mascarón, se localizaron restos de carbón en tres lugares diferentes, por lo que fueron tomadas las muestras pertinentes para que con ellas quizá se logre un fechamiento absoluto y corroboremos la edad del mascarón, el cual creemos que puede ser del Preclásico Tardío.

Al parecer el mascarón consta de tres partes; en su parte inferior tiene lo que parece ser un monstruo de la tierra, mientras que la central es un rostro antro- 


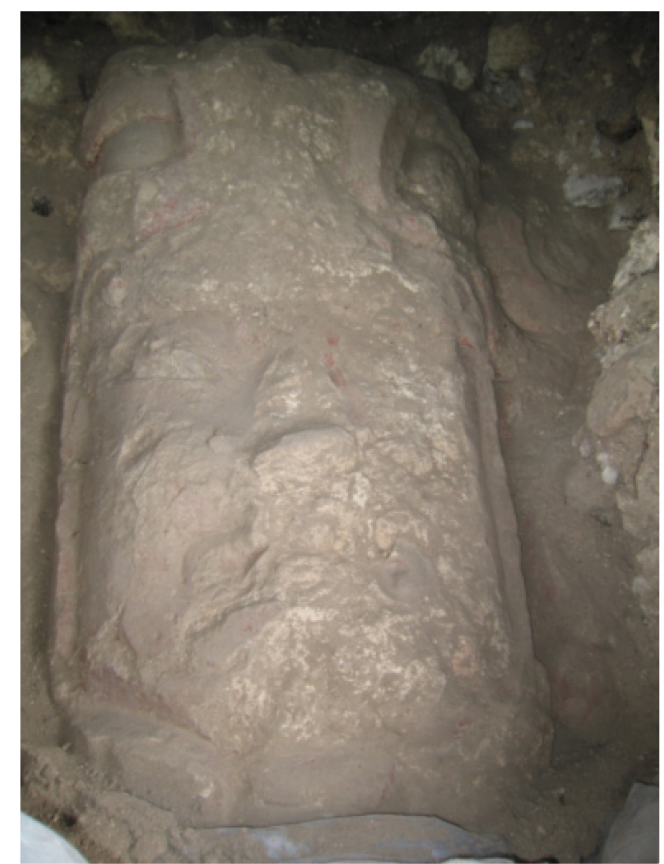

Figura 11. Rostro del Mascarón 3 de la Estructura 2

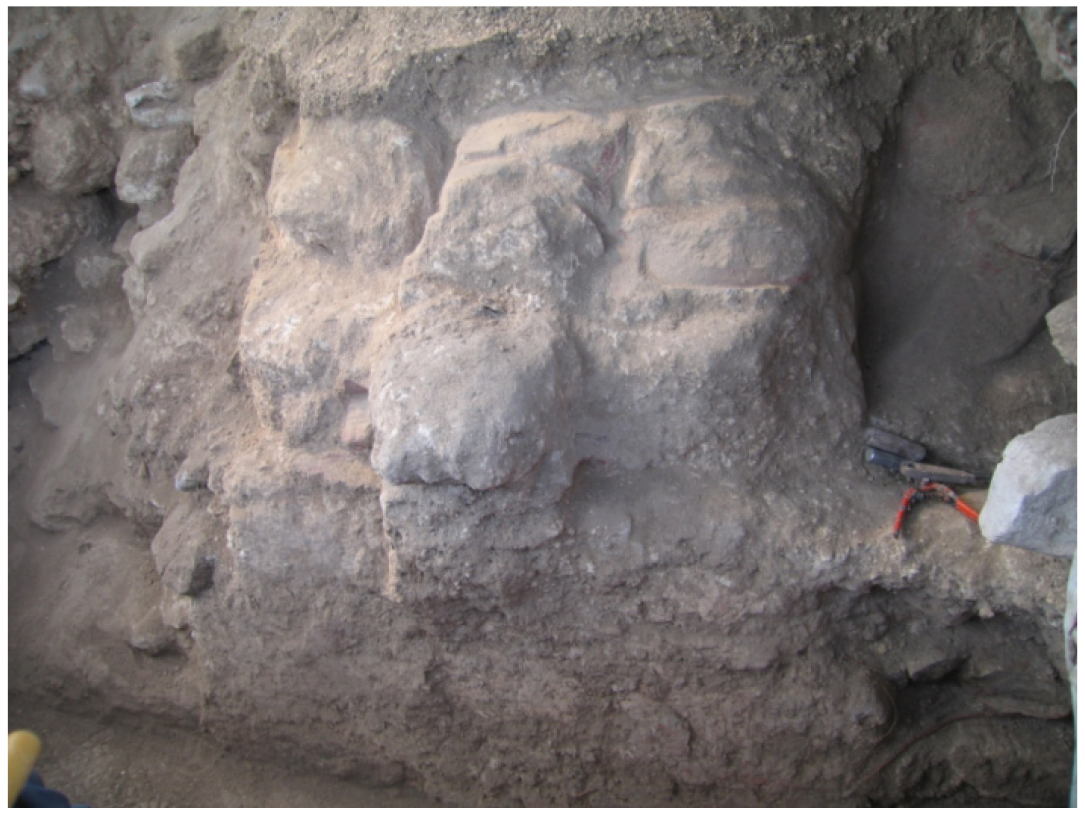

Figura 12. Parte inferior del Mascarón 3 


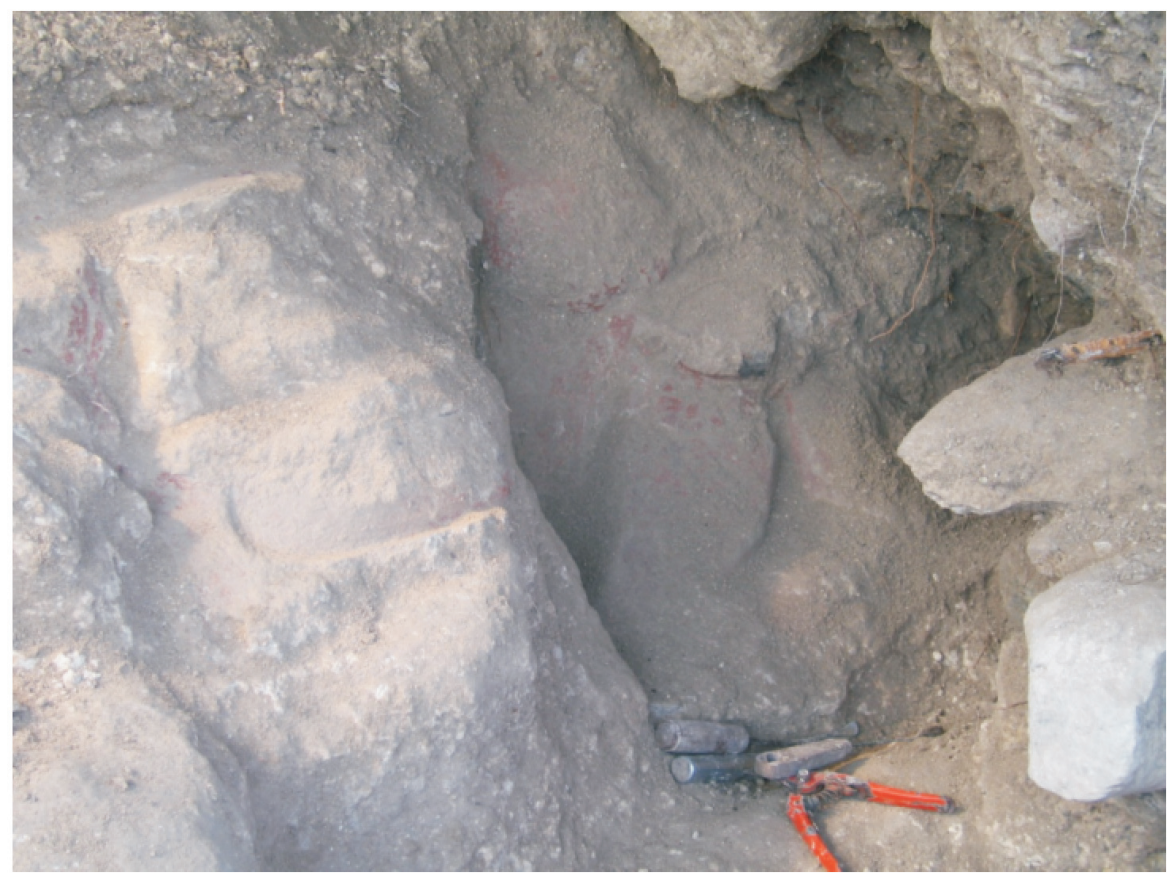

Figura 13. Detalle de la orejera del Mascarón 3

pomorfo y la parte superior podría ser una máscara o el tocado del personaje, que bien podría ser de un ave.

El Mascarón 3 de la Estructura 2 de El Tigre se halló en muy buen estado de conservación; claramente muestra los rasgos de la cara humana, frente, ojos, pómulos, mejillas, nariz, boca y mentón. Suponemos que representa a un personaje importante pintado de rojo, identificado con el Poder. Aunque en la actualidad está incompleto en la parte superior, observamos que tenía una especie de casco, en donde se puede observar que se trata de un ave; ésta cubrió la cabeza y los lados de la cara, tenía tres bandas y posiblemente al centro algún adorno.

Flanquean el rostro sendas orejeras; son de decoración muy simple, constituidas por un gran círculo con lazos o nudos y ganchos decorativos. Todo el mascarón descansa sobre un muro en talud, a su vez separados por una escalinata sin alfarda. Tanto abajo como arriba de las orejeras encontramos nudos o lazos atados y en la parte inferior se observan tres especies de hojas que se prolongan hasta llegar al piso que sostiene a la plataforma y dan la impresión de ser extensiones de las orejeras. En la parte superior del nudo se ven otros diseños como decoración.

Los símbolos que presentan estos mascarones son de realeza. Para Matheny (1987: 330) las orejeras y bandas anudadas son símbolos que se puede ligar 
posiblemente con una deificación posterior de los personajes que allí están representados. Las hojas, además, pueden aludir la fertilidad que también está vinculada con los gobernantes.

El yelmo o casco que portaban los gobernantes es un elemento que aparece desde el Preclásico Tardío como un distintivo de parentesco que denota la posesión de poder y, según Freidel y Schele (1988: 552), es uno de los objetos simbólicos de aquel entre los mayas. El soberano es una figura omnipresente en las estelas mayas del Clásico, representaba las fuerzas de ordenamiento de las distintas regiones del cosmos y el territorio del reino. Convocaba la lluvia y la fertilidad, disfrutaba de la protección de los antepasados fundadores, y poseía el poder para obligar a esas fuerzas a obrar en beneficio de su pueblo. Uno de sus deberes principales era interceder ante los dioses para asegurar una cosecha abundante; otro, la comunicación con los antepasados, de allí la importancia de representarlos en estos mascarones del Preclásico Tardío.

El Mascarón 3 de la Estructura 2 tapó un mascarón zoomorfo que representaba seguramente a un felino, a un dios más antiguo, más temprano, y este acto bien pudiera revelar la sustitución de los dioses por sus representantes, los soberanos en la tierra de los dioses. Pues los ajaw se vuelven los intermediarios entre los hombres y los dioses.

Se ha pensado que estos elementos implican la transformación del soberano en un pájaro, puesto que la posición de un soberano dependía de su capacidad para acceder al poder natural y al sobrenatural. Tales proclamaciones de su capacidad espiritual en los mascarones contribuían a validar semejante condición ante su pueblo.

\section{Los mascarones de la Estructura 4}

Esta es la estructura más alta de El Tigre (figura 14). Los trabajos que se realizaron en la Estructura $4 \mathrm{~A}$ se pueden resumir de la siguiente manera: básicamente se trabajó la parte de abajo para delimitarla, encontrándose algunas plataformas que fueron construidas tardíamente, las cuales lógicamente taparon las etapas más tempranas. Después se realizaron las exploraciones y la consolidación de los principales cuerpos de dicho edificio; en el lado este se consolidaron dos de los cuerpos, mientras que en el lado sur se consolidaron tres de los cuerpos y en el lado oeste, dos. Creemos que dos de los muros del lado sur son del Preclásico Tardío y que seguramente fueron reutilizados en las diferentes etapas.

Algo muy importante y que retrasó en gran medida las exploraciones fue el hecho de haber localizado en el lado este del edificio restos de pintura y un mascarón. Al iniciar las exploraciones del lado este y no encontrar las escalinatas que suponíamos existían allí, tuvimos que profundizar las excavaciones. En uno de los sondeos que se hicieron, siguiendo un muro se localizaron magníficos estucos modelados pintados de color crema y con círculos en rojo (figura 15); creemos que se trata de la orejera del mascarón que debe estar en ese lado. No 


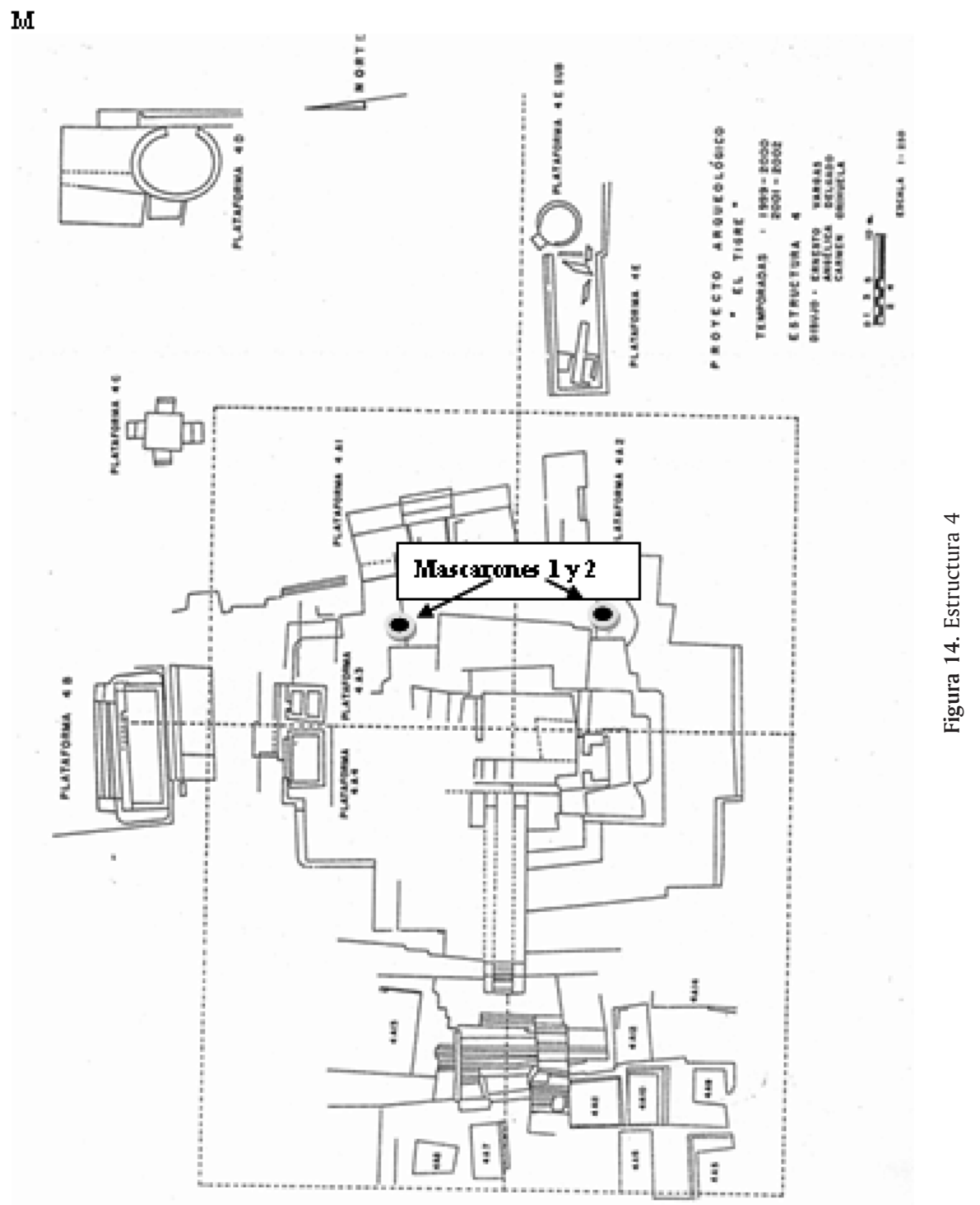


se quiso seguir con la exploración pues todavía faltaba mucho por explorar y al sacarlos tendríamos que enfrentar el problema de la conservación; además no sabíamos como aparecerían los muros y como se iban a consolidar. Lo que se hizo fue registrarlos fotográficamente y en video, taparlos y dejar para el futuro el trabajo en mejores condiciones. En el lado derecho, al hacer las exploraciones para afianzar los muros, se encontraron los restos de otro mascarón que sabíamos existía allí; se trata de un rostro humano con, al parecer, un yelmo que cubría seguramente la cabeza y las orejas. También se puede apreciar el ojo y restos en donde estuvo la nariz. Conserva restos de pintura roja y negra; además, se trata de un rostro de dimensiones grandes pues el ojo es más grande que una cabeza humana (figura 16); también fue necesario taparlo para posteriormente trabajarlo en mejores condiciones, ya que faltaba consolidar los muros que conforman ese lado de la estructura. Sabemos de la existencia de dos grandes mascarones en la Estructura 4, que será necesario trabajar en un futuro.

\section{Comentario}

En otro trabajo, "Dioses y reyes sagrados..." (Vargas, 2007), he planteado que seguramente algunos de estos mascarones son dioses; otros, en cambio, son ancestros, es decir, son representaciones de antepasados. De esa manera es que los gobernantes del Preclásico Tardío deificaban a sus ancestros para legitimar su propio poder.

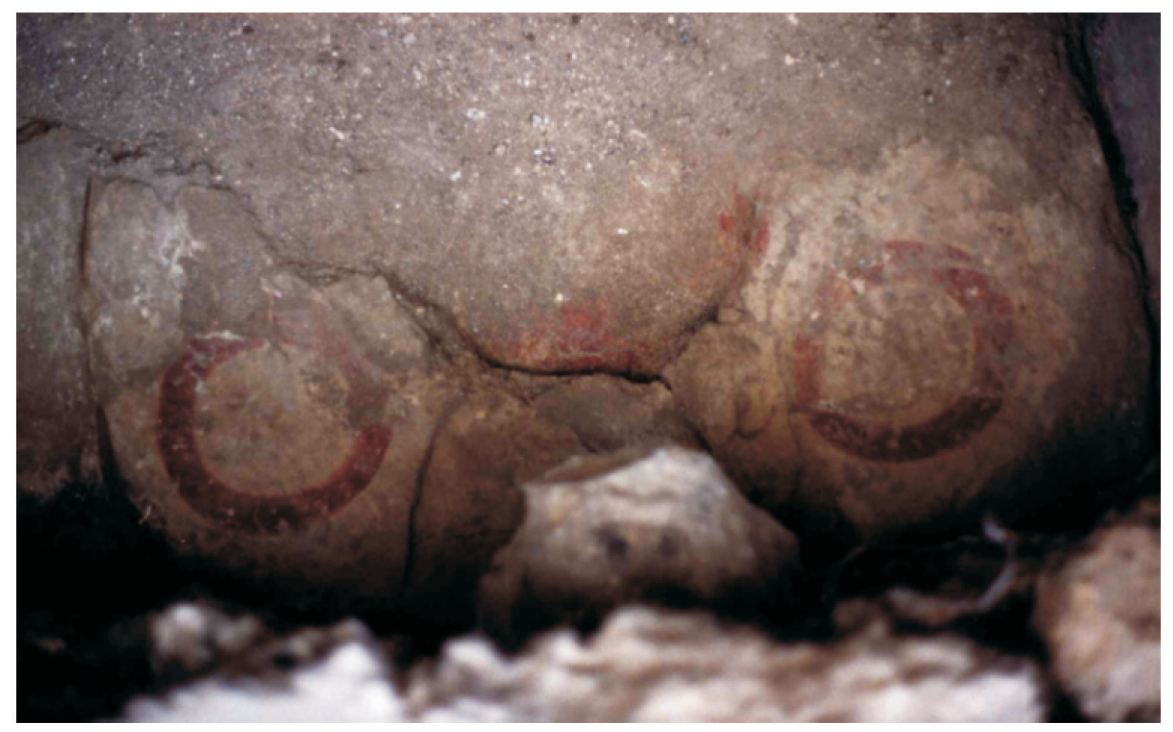

Figura 15. Restos de círculos asociados al mascarón de la Estructura 4 


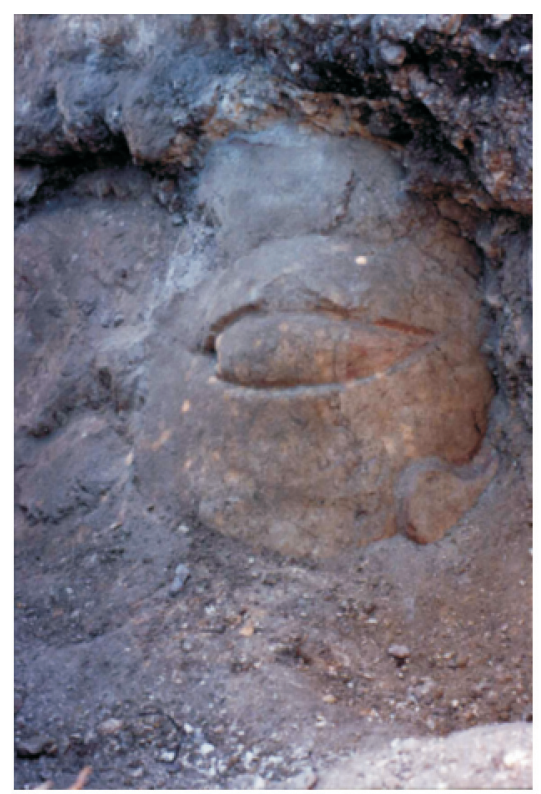

Figura 16. Mascarón antropomorfo de la Estructura 4

En El Tigre hemos encontrado mascarones en por lo menos tres estructuras, lo cual nos revela una referencia a los ancestros de los grupos de linaje, pues seguramente cada una de estas grandes estructuras monumentales son las montañas sagradas en donde se veneran a dichos antepasados.

Durante el Preclásico Tardío los mascarones en las fachadas fueron una decoración arquitectónica frecuente en las Tierras Bajas Mayas y se piensa que los temas representados simbolizaban la cosmovisión maya a gran escala. Hasta hace poco tiempo los testimonios sugerían que este estilo de arquitectura había surgido abruptamente durante el Preclásico Tardío, pero ahora se sabe que está presente en muchos sitios del mismo periodo.

En El Tigre se localizaron seis mascarones en la Estructura 1, dos en la Estructura 4 y tres en la Estructura 2. La localización de mascarones en contextos ceremoniales de subestructuras, es decir, integrados a los templos piramidales presupone su utilidad religiosa desde los inicios de las construcciones y seguramente representaban a los ancestros de los linajes que gobernaron esos lugares durante el Preclásico Tardío.

Sobre los albores de la religión en el área maya, la información es escasa o nula y faltan trabajos intensivos en sitios del Preclásico Medio y Tardío. Sin embargo, en los últimos años existen trabajos importantes e interesantes sobre sitios del Preclásico: baste citar Calakmul, El Mirador, Tikal, Nakbe, Cerros, algunos sitios más de la península de Yucatán, y los hallazgos realizados al norte 
de ésta en donde se reportan sitios importantes durante el Preclásico Medio y Temprano. Lógicamente la información sigue todavía muy fragmentada, pero cada día aparecen indicios interesantes sobre ese periodo que, sin duda, marca el origen de la cultura maya, de su religión y de la legitimación de sus antecesores en el poder.

Estos testimonios indican que durante los siglos I y il antes de Cristo se había desarrollado un sistema fuerte de gobierno centralizado, con un soberano apoyado por un grupo de nobles, sacerdotes que formaban la corte. Estos soberanos proclamaban ser descendientes directos de los dioses, y dado que esto les confería el derecho de gobernar los destinos de su pueblo, no perdían ninguna oportunidad de recalcar su naturaleza divina ante los súbditos. Los dirigentes emprendieron grandes obras y programas para exhibir su autoridad y la de sus dioses; por eso mandaron construir edificios y mascarones a sus antepasados deificados puesto que la posición de un soberano dependía de su capacidad para acceder al poder natural y al sobrenatural. Tales proclamaciones de su capacidad espiritual en los monumentos públicos contribuían a validar semejante condición ante su pueblo.

Durante el Clásico, en el centro del cosmos se sitúa el k'uhul ajaw ("señor divino") ya que se consideraba a sí mismo como un axis mundi, como eje, y en ocasiones se muestra con un ropaje que simboliza el árbol del mundo en su faja ceñida a la cintura. Pretendía desempeñar tanto el papel del hombre que mantiene el orden terreno como el del dios que mantiene y determina el orden cósmico; a través del ritual controlaba los fenómenos meteorológicos, astronómicos y naturales que revestían importancia para los ciclos agrícolas.

Cada fin de k'atun se hacían ceremonias de renovación y se recreaba el acontecimiento de la creación. El soberano hacía escenificaciones rituales en que destruía simbólicamente el mundo y lo creaba de nuevo. La creación fue el inicio del tiempo y de todo el orden. Fue un modelo para la convivencia humana, de la cual el soberano era el encargado.

Los soberanos mayas conmemoraban sus actos rituales a través del arte y la arquitectura monumental. Y los señores del Preclásico Tardío de El Tigre usaron la arquitectura para reproducir la topografía del universo; se sirvieron de los mascarones para trasmitir la condición divina de sus antepasados, de sus dioses y la suya propia, pues ellos fueron los que intervenían ante los dioses para asegurar la cosecha abundante, eran los que convocaban la lluvia y la fertilidad y poseían el poder para obligar a esas fuerzas sobrenaturales a través del ritual a obrar en beneficio del pueblo. 


\section{BIBLIOGRAFÍA}

Fields, Virginia M.

1989 The origins of Divine Kingship among the Lowland Classic Maya. Tesis doctoral, Austin: University of Texas at Austin.

Freidel, David A. y Linda Schele

1988 "Kingship in the Late Preclassic Maya lowlands: the instruments and places of ritual power", American Anthropologist, 90 (3): 547-567. Arlington, Virginia: American Anthropological Association.

1993 El cosmos maya. Tres mil años por la senda de los chamanes, traducción de Jorge Ferreiro Santana. México: Fondo de Cultura Económica.

Garben, James F. et al.

2004 "Middle Formative Prehistory of the Central Belize Valley", The Ancient Maya of The Belize Valley: Half a Century of Archaeological Research, pp. 27-45, James

F. Garber (ed.). Gainesville, Florida: University Press of Florida.

Hansen, Richard

1990a Excavations in the Tigre Complex, El Mirador, Peten, Guatemala. Provo, Utah: Brigham Young University (Papers of the New World Archaeological Foundation, 62).

1990b "Los orígenes de la civilización maya: perspectiva desde el Norte de Petén", Cuarto simposio de Arqueología Guatemalteca. Guatemala: Museo Nacional de Arqueología y Etnología.

Houston, Stephen D. y David Stuart

2001 "Peopling the Classic Maya Court", Royal Courts of the Ancient Maya: Theory, Comparison, and Synthesis, vol. 1: pp. 54-83, T. Inomata y S. D. Houston (eds.). Boulder, Colorado: Westview Press.

Matheny, Ray T.

1987 “El Mirador”, National Geographic, 172 (3), septiembre: 316-339.

Mathews, Peter y John S. Justeson

1984 "Patterns of Sign Substitution in Mayan Hieroglyphic Writing", Phoneticism in Mayan Hieroglyphic Writing, pp. 185-231, J. S. Justeson y L. R. Campbell (eds.). Albany, Nueva York: State University of New York.

Okoshi Harada, Tsubasa

1995 "Gobierno y pueblos entre los mayas yucatecos posclásicos". Revista Universidad de México, 534-535: 22-27. México: Universidad Nacional Autónoma de México.

Vargas Pacheco, Ernesto

2001 Itzamkanac y Acalan. Tiempos de crisis, anticipando el futuro. México: Universidad Nacional Autónoma de México, Instituto de Investigaciones Antropológicas. 
Vargas Pacheco, Ernesto

2007 "Dioses y reyes sagrados. El mito de la creación y la legitimación de la realeza entre los mayas del Preclásico Tardío", Encuentro Pueblos y Fronteras 2007. Arte y religión en el periodo formativo: México y Centroamérica. San Cristóbal de Las Casas, Chiapas. Manuscrito. 
